\title{
Open Government and (Linked) (Open) (Government) (Data) ${ }^{1}$
}

Free accessible data of the public sector in the context of open government

\author{
Christian P. Geiger*, Jörn von Lucke** \\ *Am Seemooser Horn 20, 88045 Friedrichshafen, christian.geiger@zu.de \\ ** Am Seemooser Horn 20, 88045 Friedrichshafen, joern.vonlucke@zu.de
}

\begin{abstract}
This article explores the opening and the free usage of stored public sector data, supplied by state. In the age of Open Government and Open Data it's not enough to simply put data online. It should, rather, be weighed out whether, how and which supplied public sector data can be published. Open Data are defined as stored data which could be made accessible in the public interest without any restrictions for usage and distribution. These Open Data may be statistics, geo data, maps, plans, environmental data and weather data in addition to materials of parliaments, ministries and authorities. The preparation and the free access to existing data permit varied approaches to the reuse of data, which is discussed in the article. In addition, impulses can be given for Open Government - the opening of state and administration, to more transparency, participation and collaboration as well as to innovation and business development. The Open Data movement tries to get to the bottom of current publication processes in the public sector which could be formed even more friendly to citizens and enterprises.
\end{abstract}

Keywords: Open Data, Open Government Data, Linked Data, Linked Open Government Data, Open Government, Transparency, Participation, Collaboration, Cooperation.

M ajor changes in technology, society and politics are converting_the conduct and the process of doing politics, administration and the relationship between politicians, public servants and citizens. In the technological context innovative end devices and fast network as well as mobile broadband infrastructure are offered by the telecommunications providers. More and more smartphones are used by consumers. Society is changing too. Participation and accurately-fitting governmental services are demanded. The political culture shifts from "information" towards "communication" orientation. In an increasing number of cases, politics involves citizenparticipation; producing better solutions than without them.

Transparency, participation and collaboration are the main issues of the integration of citizens in the paradigm of Open Government. One requirement for realizing these central points is the free access to certain data. Because administrations have large amounts of data which could be made accessible for the purpose of the Open Data movement, the discussion about the opening process, data protection considerations and secret reservations of data is fundamental. This article analyses the potential of free accessible public sector data, which can become important in the political considerations of open government. To explore the opening and free usage of stored public sector data, supplied by the state, we discuss first the common understanding of Open Data, Linked Open Data, Open Government Data and Linked Open Government Data. In the second chapter, the added value of freely-accessible public sector data is outlined and critically argued. In the third chapter, possible problems and general challenges of Open Government Data for public administrations at the different administration levels are discussed. The analysis in the fourth chapter concludes the areas of application, benefits, strengths, weaknesses, opportunities and threats, exemplified in the former text. The paper ends with a formal conclusion.

\footnotetext{
${ }^{1}$ This article is based upon the "Open Government Data" survey of the TICC (von Lucke/Geiger, 2010) and published as an extended version of the already published article "Open Government Data" in the Conference Proceedings of the CeDEM11 (Geiger/von Lucke, 2011).
} 


\section{Open Government}

\subsection{Open Government as an Umbrella Term}

Open Government acts as an umbrella term for many different ideas and concepts. The narrow definition of Open Government consists of transparency, participation and collaboration of the state towards third actors like the economy or the citizenship. Most often, Open Government is equated with E-Government and the usage of Information and Communication Technologies. This general equation of a theoretical paradigm (Open Government) and the tool-kit or rather its instrument (Information and Communication Technologies) is incorrect. Thus, the discussion about the basis of an effective realization and implementation of Open Government is seen in the discussion about Open Data.

In addition to the narrow understanding of Open Government (transparency, participation and collaboration) there is also a wider definition of Open Government and its impact to govern: The socalled "family of open government" consists of more than Open Data, Transparency, Participation and Collaboration. Further dimensions within the discussion about Open Government are the debates about Open Access and Open Knowledge as well as Open Innovation and Open Societal Innovation. Furthermore, Open Process Chains and Open Value Added Economic Chains can be discussed practically besides Open Statecraft and the Open Policy-Cycle theoretically. Further contents are Open Source, Open Standards as well as Open Interfaces (Open APIs) and the Open Markets Approach. This compilation of different ideas which can be included within the Open Government paradigm is exemplary and not conclusive.

Regarding this multiplicity of concepts and ideas, Open Government is rather more than a single concept with a narrow thematical focus. Open Government must be seen as a wide concept with a broad range of aspects and opinions.

\subsection{Open Government Trends}

Beside the different terms and concepts within the paradigm of Open Government, one can observe seven different Open Government Trends. These trends describe the characteristics and some features of the concept of Open Government. Like the seven characteristics which describe the essence of the Web 2.0 on an abstract level, there are also seven characters which constitute Open Government and the way to determine Open Government. Von Lucke defines Open Government by the following attributes: (I) Building of new communities, (II) Information and Open Data, (III) Common Editing and Design, (IV) Common Consulting and Discussion, (V) Common Decision Making and Ordering, (VI) Common Action and Programming and (VII) Common Commenting and Rating of political and administrative topics (von Lucke, 2012 p. 166\}.

- Building of new communities: Due to innovative information and communication technologies, new communities can be created on the internet for information, participation and collaboration. Social networks are enabling a common workspace, (a)synchronous work time and ad-hoc networking opportunities.

- Information and Open Data: More and more administrations are publishing existing governmental data for re-use and recovery to create applications with an added value.

- Common Editing and Design: By using new technologies, actors can edit and design concepts together without any transaction costs.

- Common Consulting and Discussion: Positive irritations are the critical factor for good and innovative results and sustainable teamwork, concepts can be harmonized in the network.

- Common Decision Making and Ordering: Regarding the Policy Cycle, developed concepts can be voted on and decisions can be taken.

- Common Action and Programming: The conversion of ideas into reality, for example in Apps or Mash-Ups can be realized as a group experience within the Internet or at so called Hackdays. 
- Common Commenting: At the end, the different proposals, results or implemented projects can be monitored and discussed by all of the participants of the process.

Due to this, Open Government trends are especially focused on common action, based on an open political and administrative process. The Open Government trends are compulsory not synchronic but asynchronic. The intensity of the several trends and the relationship between the different Open Government Trends are not discussed yet.

\subsection{Open Government Collaboration}

Depending on this functional approach, Open Government enables the usage of external resources for creating added value, formally contributed to by internal resources. Instead of buying external services, the creation of products and services by collaboration between administration and citizenship can be an activating and efficient alternative. The question of make-or-buy services in several different public areas can be answered by the prosumerism-approach in collaborative aspects of the public administration and the citizenship: Von Lucke describes ten different possibilities of collaboration, which can be conducted within the presented policy cycle. It's about common and collaborative (I) financing (crowd financing), (II) knowledge management, (III) project work in cyberspace, (IV) committee work, (V) work because of process, (VI) realization of public mission, (VII) honorary position, (VIII) peer reviewing, (IX) monitoring and evaluation and (X) innovation processes (von Lucke, 2012, 7ff.).

\subsection{Open Government Within the Policy-Cycle}

Due to the (r)evolution towards an Open State, including Open Politics and Open Administration, the path to a Government 2.0 seems possible. Adopting the described Open Government Trends to the well-known concept of a regular Policy Cycle, a circular information and integration of citizens into the political and administrative process seems possible. Information and Communication Technologies enables a better integration of third actor into the former political steps of (I) problem definition, (II) agenda setting and (III) decision making. The rather administrative steps within the policy cycle like (IV) implementation, (V) monitoring and (VI) evaluation of policies can be designed more and more accessible to third actors.

By the new perception of a Policy Cycle using the paradigm of Open Government on the one hand as well as Information and Communication Technologies on the other hand, a new quality of information, participation and collaboration between state and third actors is possible.

Due to the role of information and open data as the basis for a successful implementation of Open Government, the question about the role, the requirements, the challenges as well as the success factors of Open Data, Linked Open Data, Open Government Data and Linked Open Government Data is discussed in the following sections of this paper.

\section{From Open Government to Open Government Data}

\subsection{Open Data}

Organizations increase transparency when they expect valuable external influences and are interested in a more intensive interlinking with their surroundings, without the risk of getting damaged. This assumes readiness for an opening process which considers impulses, discourses and exchanges as constructive and welcome. One approach is the free and open access to data, information, knowledge and sources (von Lucke/Geiger, 2010). Thus, the first understanding of openness is the proceeding of the Open Knowledge Foundation (OKF, 2006). Works are open if they are available to everybody for less than their reproduction costs, if it is permitted to re-use them, create modifications and derivatives, open file formats are used, nobody is discriminated against during usage and no restrictions exist for possible purposes (OKF, 2006). This approach 
can be transferred to data, information and knowledge. Knowledge can be realized as the result of the interlinking of information in society, in organizations and in the heads of individuals. Information becomes content of knowledge if they are contextualized to an adequate possibility of using them. Each piece of information contains a certain meaning. In this context, information is understood as machine-readable data combined in a special syntax. Continuous functions are used for the presentation of analogous data, signs for digital data (North, 1998; Hansen \& Neumann, 2009). Due to these considerations and characteristics the following working definition of "Open Data" can be deduced (Open Data - OD):

Open Data are all stored data which could be made accessible in a public interest without any restrictions for usage and distribution.

Content of Open Data could be education material, geo data, statistics, traffic data, scientific publications, medical studies or radio and television programs. Open Data combines not only stored data of the public sector, but also includes data from businesses, universities, broadcasting stations or non-profit-organizations (von Lucke, 2011).

\subsection{Linked Open Data}

The cross linking of Open Data via the Internet and the World Wide Web as "Linked Open Data" (LOD) offers the possibility of using data across domains or organizational borders for statistics, analysis, maps and publications. By linking these data, interrelations and correlations can be understood quickly. Added value is created when stored data - unconnected before - is combined and new conclusions can be achieved. The low-threshold addressability of stored data in the Internet, especially, helps reduce existing barriers. By aid of "Uniform Resource Identifier" (URI) and "Resource Description Framework" (RDF), parts of data, information and knowledge can be prepared, shared, exported and connected. Due to this consideration, the following working definition to "Linked Open Data" (LOD) can be deduced:

Linked Open Data are all stored data connected via the World Wide Web which could be made accessible in a public interest without any restrictions for usage and distribution.

This approach enforces the cross-linking of free stored data of different sources, without any restrictions in combination and usage. Because of Linked Open Data and open interfaces (APIs), applications (apps) and instruments (tools) can be created, which support fully automated researches, surveys, monitoring and reporting. The concept of Linked Open Data rests upon Tim Berners-Lee (2006). New knowledge can be created and visualized by an interlinking within a linked open data cloud. A popular illustration of this data cloud was designed in October 2007 and refurbished for several times ${ }^{2}$. The cloud includes numerous stored data of private and public stock of the semantic web. For example, DBpedia, GeoNames, EuroStat, Open Street Map and Linked GeoData are embedded.

\subsection{Open Government Data}

Regarding the public sector, the characteristics of drafted thoughts about Open Data and Linked Open Data must be more considered. For sharpening the definition, a common understanding of "Open Government Data" (OGD) must be found. A fundamental impulse is provided by the ten principles for open government information of the Sunlight Foundation (Sunlight Foundation, 2010). The combination is the result of a revision of the "Sebastopol-List" (Open Data Working Group, 2007). The Sebastopol-List has been made by 30 US-American Open-Government-supporters, the lead taken by Carl Malamud and Tim O'Reilly. Each of the ten principles describes a certain form of openness for the public sector.

\footnotetext{
${ }^{2}$ http://richard.cyganiak.de/2007/10/lod/lod-datasets 2011-09-19 colored.png
} 
The following set concludes the essential thoughts (Sunlight Foundation) ${ }^{3}$ :

1. Completeness

2. Primacy

3. Timeliness

4. Ease of Physical and Electronic Access

5. Machine readability

6. Non-discrimination

7. Use of Commonly Owned Standards

8. Licensing

9. Permanence

10. Usage Costs

For labeling freely-accessible stored data of the public sector, the item "Open Government Data" (OGD) seems better:

Open Government Data are all stored data of the public sector which could be made accessible by government in a public interest without any restrictions for usage and distribution.

This denomination refers explicitly to the public sector. At the same time it excludes the publication of all stored data of the public sector which should remain confidential, are private or contains industrial secrets and shouldn't therefore be published. If the stored data were procured by responsible administrations, they could be screened, searched through, filtered, formatted, monitored and edited. Those data could be statistics, geo data, maps, plans, environmental data, governmental information, accounting data, laws and directives, and other publications. Some exemplary realizations as apps, mash-ups and services based on open government data can be found in the web-based portal "data.gov" of the British Government and the "DataSF App Showcase" of the City of San Francisco. For a common background, the government should open not only raw data, but also information and publications based on this data. The usage of this data, information and publications would be desirable for the reuse of public sector information in general, especially referring to the EU Directive 2003/98/EG (von Lucke, 2011).

\subsection{Linked Open Government Data}

Regarding the thoughts about Linked Open Data, the concept must be devolved to the stored open data of the public sector. The working definition for Linked Open Government Data (LOGD) is:

Linked Open Government Data are all stored data of the public sector connected by the World Wide Web which could be made accessible in a public interest without any restrictions for usage and distribution.

The connection of these stored data by World Wide Web allows the utilization of these data behind domains and organizational boarders. In the current version of the linked open data cloud ${ }^{7}$ already included Open Government Data is visualized by turquoise color. This contains, for example, selected stored data of EuroStat ${ }^{8}$ and big parts of the British Government public sector information.

\footnotetext{
${ }^{3}$ http://sunlightfoundation.com/policy/documents/ten-open-data-principles/

${ }^{4}$ http://www.data.gov/pastfeatureddatasets

${ }^{5}$ http://data.gov.uk/apps

${ }^{6}$ http://datasf.org/showcase

${ }^{7}$ http://richard.cyganiak.de/2007/10/lod/lod-datasets 2011-09-19 colored.png

${ }^{8}$ http://epp.eurostat.ec.europa.eu/portal/page/portal/statistics/search database
} 
While he was working for the British Government, Tim Berners-Lee emphasized that the public data should be interlinked by the World Wide Web ${ }^{9}$.

\subsection{Free Accessible Government Data}

A successful implementation of freely-accessible government data in European countries could not be achieved by simply copying foreign concepts of modernization for state and administration, because administration is limited by perceptions, traditions and cultures in the public access and transparency debate. So, each administration should produce its own ideas, filling-out the concept of freely-accessible government data. The presented working definitions referring to Open Data, Linked Open Data, Open Government Data and Linked Open Government Data could be the fundament of this discussion process.

Politics and administration need such an opinion-forming process because a pragmatic handling of existing stored data is demanded. State and administration are in a paradigm change in the era of Open Government. Free accessible data can be used as tools for opening and influencing contents, structures, organizational chains and decision-making processes. For a successful solution of these problems, a three-rated paradigm shift in politics and administration towards a publically new, politically and administratively openness is expected (IG Collaboratory, 2010):

- The first paradigm affects the concept of public and secrecy of data: Old paradigm: Everything is secret, if it's not explicitly marked as public,. New paradigm: Everything is public, if it's not explicitly marked as secret,.

- The second paradigm affects range, type and point in time of the publication of data: Old paradigm: range and time of publication are determined by public authority. Often, inspection of files is on application, based on the freedom of information act. New paradigm: All data, not determined by a qualified data privacy protection or data security, are fully published proactive and contemporary.

- The third paradigm affects the rights of use of the published data: Old paradigm: published data are permitted to be inspected for private use. Further usage is reserved and can be allowed on demand. New paradigm: published data are useable by everybody for everything including commercial usage without any restrictions exempt from charges. This contains the possibility of editing and distributing of the public data.

Such a paradigm change initiated by the open data initiative implicates an essential cultural shift for politics and administration. By moving away from the current principles of secrecy, openness and transparency the democratic rights of control of the citizens would be strengthened. If data, information and knowledge were to be made available to everybody, the social transfer to a knowledge society will be enforced. The provision of free accessible data in a "Allmende" (common data cloud) (Reinermann 1986, p. 9) and the possibility of using and editing the data can speed up the innovation process intensively, software developer can create own services, interfaces and applications based on these data. Referring these changes, the public administration has to discuss itself which definition of freely-accessible government data should be used. One solution could be that the own suggestions depending completeness, primacy, timeliness, ease of physical and electronic access, machine readability, non-discrimination, use of commonly owned standards, licensing, permanence and usage costs differ from the presented way. A classification of the existing data in politics and administration could include worthwhile impulses in the decisionmaking process. Currently, open and proprietary data formats are used, but not all data formats are published for the public and not every interested party can influence those specifications. All over the world, different license schemes exists, using access rates, modification and distribution of data

\footnotetext{
${ }^{9}$ http://data.gov.uk/linked-data
} 
as business model. The access to stored data can be granted without charges or other barriers. But there also can be business models using memberships, transaction fees, commission fees and data volume fees. If there are stored data, collected by public order, but not declared as public domain, they often owned by the nation, the states or the local authorities. Alternatively, a company or an association could get the permission to refine the stored data and sell them for money. Service providers can adopt activities by collection, grouping, preparation, finishing and improvement of data. Data can be used for public and private intention. Depending on the scope of application, data are contextualized to geography, law, ecology, economy, administration, sociology or society. They can be used to generate facts and information. Data can be provided by interfaces, as raw data and independent services (Schieferdecker, 2010 \& Davies, 2010).

With regard to the data formats used and the standardization processes in the public sector, formats and processing must be reflected. The illustration in the first table describes data formats of possible guidelines for public sector, because they are machine readable, reproducible and open.

Table 1: Different Types of Formats (Gray, 2009, p.10; supplemented and adopted by von Lucke/Geiger 2010, p.9)

\begin{tabular}{|c|c|c|c|}
\hline $\begin{array}{c}\text { Text, Spreadsheet and Images } \\
\text { Formats }\end{array}$ & 123 & Geo Data Formats & 123 \\
\hline $\begin{array}{l}\text { Text (.txt) } \\
\text { Comma Separated Value (.csv) } \\
\text { Hypertext Markup Language (.html) } \\
\text { Extensible Markup Language (.xml) } \\
\text { Resource Description Framework (.rdf) } \\
\text { Open Document Formats (.odt, .ods,) } \\
\text { Newsfeed/Webfeed Syndication (.rss) } \\
\text { Portable Document Format(.pdf) } \\
\text { Microsoft Word (.doc/.docx) } \\
\text { Microsoft Excel (.xls/.xlsx) } \\
\text { Microsoft Rich Text Format (.rtf) } \\
\text { Graphics Interchange Format (.gif) } \\
\text { JPEG - format (.jpg, .jpeg) } \\
\text { Portable Network Graphics (.png) } \\
\text { Tagged Image File format (.tiff, .tif) } \\
\text { GEO - TIFF - Format (.geotiff, .tiff, .tif) }\end{array}$ & $\begin{array}{l}\sqrt{ } \sqrt{ } \\
\sqrt{ } \sqrt{ } \\
\sqrt{ } \sqrt{ } \\
\sqrt{ } \sqrt{ } \\
\sqrt{ } \sqrt{ } \\
\sqrt{ } \sqrt{ } \\
\sqrt{ } \sqrt{ } \\
x \sqrt{ } \\
x \sqrt{ } x \\
\sqrt{ } \sqrt{x} \\
\sqrt{ } \sqrt{x} \\
x \sqrt{ } x \\
x \sqrt{ } \\
x \sqrt{ } \\
x \sqrt{ } x \\
x \sqrt{ } x\end{array}$ & $\begin{array}{l}\text { Geography Markup Language (.gml) } \\
\text { GPS Exchange Format (.gpx) } \\
\text { Keyhole Markup Language (.kml) } \\
\text { Drawing Interchange File Format (.dxf) } \\
\text { Autodesk Drawing Format (.dwg) } \\
\text { ESRI Shapefile Format (.shp,.shx,.dbf) } \\
\text { Enhanced Compression Wavel. (.ecw) } \\
\text { MrSID Format (.sid) } \\
\text { Normbas. Austauschschnittst. (NAS) } \\
\text { Einheitl. Datenbankschnittst. (EDBS) } \\
\text { BGRUND (BW) } \\
\text { WLDGE - Format (.wld) }\end{array}$ & $\begin{array}{l}\sqrt{ } \sqrt{ } \\
\sqrt{ } \sqrt{ } \\
\sqrt{ } \sqrt{ } \\
\sqrt{ } \mathrm{V} x \\
\sqrt{ } x x \\
\sqrt{ } \sqrt{ } x \\
\sqrt{ } x x \\
\sqrt{ } x x \\
\sqrt{ } \sqrt{ } x \\
\sqrt{ } \sqrt{ } x \\
\sqrt{ } \sqrt{ } x \\
\sqrt{ } \sqrt{ } x\end{array}$ \\
\hline
\end{tabular}

\section{Added Value of Freely-accessible Public Sector Data}

Based on these drafted thoughts of a careful opening of government and administration, one should ask which advantages and added value are included in a free access to stored public sector data for citizens, the economy, administration and society? Why do we need that? Why do we want to know this? Who interprets these data seriously? What do we want to use them for? In the debate towards the opening of government and administration and the potentials of a re-use, transparency, participation, collaboration and innovation, one can find the answers.

- Opening of government and administration: The concepts of freely-accessible data are an essential component of open government. The opening of multiple raw data is demanded for creating more transparency, citizen orientation, wider open administration and positive press 
work. A well informed publicity and the associated openness is strengthening the citizenship overall (von Lucke/Geiger, 2010).

- Re-use and recovery: Unmodified data can be re-used in a second context, recovered data, based on existing data sets can be modified and visualized. The form of re-use or recovery of data can be described in guidelines of the public sector.

- Transparency: Transparency is one of the three goals of open government in addition to participation and collaboration. Hence, the potentials and opportunities of additional transparency in government and administration are outstanding relevant. Through data-based transparency, decisions, actions and the consequences are visible and comprehensible. The trust in state and participation can be increased. (IG Collaboratory, 2010).

- Participation and collaboration: Freely-accessible stored data enables the potential for political and social collaboration. Each provision of public data increases participation (Klessmann, 2010), dialogues can be conducted more intensively, in a personal way (IG Collaboratory, 2010). This contains participation as well as collaboration in terms of the strong involvement of citizens. At the same time, citizens produce and consume public goods; they are "prosumers". Citizens can appear as well-informed actors, using low-threshold information for high quality discussions (Lundy, 2010).

- Better governance: Citizenship and the public can be informed on time and in more detail about the work of politics and administration; results can be discussed, and problems can be solved by using collective intelligence.

- Open innovation: There is a great potential for social innovations and economic development in (re-)using and distributing freely-accessible data. Citizens and developers are no longer reliant on politics or administration; they could implement ideas by themselves. Idle data can be scanned, visualized, analyzed and refined, processes and services can be re-engineered. (IG Collaboratory, 2010).

- Economic development: By interpreting the data, new applications, products and services, business models and process chains can be developed and new jobs provided. At the same time, the quality of life for citizens and the quality of locations for companies can be increased. (IG Collaboratory, 2010 \& Klessmann, 2010).

\section{General Challenges of Open Government Data}

For a successful implementation, the pure knowledge of the potentials and important data is falling far short. A set of challenges must be managed too: the legally-allowed framework must be defined. The protection of data privacy must be ensured. Information must be prepared and necessary precaution against wrong conclusion must be done. This can be assured by change management, considering the structure and the culture of the administration and removing possible strategy deficits.

- Legal framework: There are different national and international laws about open data and transparency, controlling information- and publishing requirements. European directives must be transformed into national law. For the people and the press, not all requests concerning the usage of open data are decided in a positive way. Especially, if security concerns and confidential restrictions exist (Gierow, 2010).

- Data about protection of public interest, governmental decision-making process, personal data, intellectual property and industrial secrets must remain unpublished. Publications, not restricted by any protection requirements or freed by the concerned person are uncomplicated. Sometimes, a fair balance of the general public and the individual interests must be discussed. The originally designated purpose should be traced. The open data approach can intensify efforts for transparent instruments used for legal execution. The risk of being in the pillory can reduce breaches of law by deterrence. Because of data protection, the recognition and retracement of anonymized data of persons, groups or companies must be made impossible. 
- Flood of information and preparation of information: Agencies and regional authorities, not yet dealing with freely-accessible data, face a big challenge regarding their existing stored data. It must be defined, when and which data can be published in machine-readable formats and how to deal with approved publishing formats. Furthermore, the access to lapsed or historical data must be checked: the quality of data must maintain the expected high quality level of public authorities. The access can be widened to information services, information platforms, portals, interfaces, tools, mash-ups or mobile apps.

- Fear of misinterpretation and misreading: Third parties can take data, edit and publish them referring to the original sources. If a small error has crept in, it is acceptable but if the author is distorting the data in order to gain advantage or for damaging to someone's reputation or defaming certain groups, conclusions must be reached. But how to deal with wrong interpretations, irresponsible published mistakes, gutter press and explosive data content? A fair handling of information by all users must be sought.

- Process re-engineering, personal capacities and financing: Closely connected to the described questions in content, different organizational challenges, are also possible, especially in instruction and financing. Resources could be assured before and during the project for ongoing support and updates. Refunding can take place through additional revenues and savings. It is important that employees are informed of the change process with sufficient notice. The pros and cons of the open government data approach must be discussed before introduction of the project. (Torkington, 2010 \& Deloitte Research, 2010).

- Structure and culture of the public sector: For structure and culture, the shift to open government data is combined with a transculturation. Knowledge comprises power. With the introduction of open government data, the administration passes a part of its power back to the society. This could lead to a conflict of power (IG Collaboratory, 2010). Thus, the resulting advantages of openness and transparency have to convince. The result of repressed information can be a publication of documents at whistleblower-platforms like "wikileaks" or "openleaks". If data are freely-accessible, some shrinking former business models of the public sector can create resistance (MICUS, 2003).

- Strategic framework for overcoming of existing strategy deficits: In spite of the Granada strategy - supporting open government by bundling and publishing consumer information and environmental and geo data - Germany has no existing vision developed for handling free accessible data (Granada Strategy, 2010). First steps were taken in autumn 2010. By gaining experience in implementing prototypes, experiences and making mistakes, politics and administration could learn step by step. Regarding this, it could be a long and difficult road to a multilevel open government data strategy. So, there is the need for a short framework of strategy for opening politics and administration, containing general guidelines to the accessibility of data, information and knowledge, standards, interfaces and coordination.

\section{Compact Analysis of Open Government Data}

In addition to the drafted potentials and added value in Chapter 2, some current challenges of Open Government Data have been outlined in Chapter 3. Both of these issues - added value and challenges - should take part in the compact analysis in table 2. The aim of this illustration is the support of the change process within the different administrations and the information of the different actors, by clarifying the positive as well as the negative aspects of Open Government Data. Thus, the compact analysis of "strengths", "weaknesses", "threats" and "opportunities" is supplemented with possible "areas of application" and the "benefits" of Open Government Data. Weaknesses and threats should be observed: There must be a standing rule about copyright, data protection or informational self-determination before and after using the data, the correctness of the supported data must be assured. For an increasing technical interoperability, a modulated solution, providing different Application Programming Interfaces (API) should be preferred. Misinterpretations of data will be published but should be avoided if possible, to inhibit populism. Regarding the impact for the citizenship, the cultural shift kicked off by Open Government Data 
also offers opportunities for the public administration. Good management of the administration can reduce the negative aspects and strengthen the positive impact, like the activation of citizenship, promotion of economic development and the modernization of the public administration, including an innovative climate for citizens, administration and economy. Time will tell if the positive aspects prevail.

Table 2: SWOT-Analysis of Open Government Data

\begin{tabular}{|c|c|}
\hline Areas of application & Benefits \\
\hline $\begin{array}{l}\text { - Generating facts \& information } \\
\text { - Information of society } \\
\text { - Visualization of complex data } \\
\text { applications and services based on data } \\
\text { and interfaces }\end{array}$ & $\begin{array}{l}\text { - Strengthening of society by a cautious } \\
\text { opening of the state } \\
\text { - Re-use and recovery } \\
\text { - Transparency, participation, collaboration } \\
\text { - External impulses of innovation } \\
\text { - Usage of collective intelligence }\end{array}$ \\
\hline Strengths & Weaknesses \\
\hline $\begin{array}{l}\text { - } \text { More intensive usage of stored data of } \\
\text { - } \text { Opublic authorities } \\
\text { - } \text { Diversity and connecting of data } \\
\text { - } \text { Confidence-building measures } \\
\text { - Input for economic development }\end{array}$ & $\begin{array}{l}\text { - } \text { Cultural shift for the public administration } \\
\text { - Danger to current business models } \\
\text { - Uncertainty of existing copyright laws } \\
\text { - Long standardization processes } \\
\text { - Digital divide }\end{array}$ \\
\hline Opportunities & Threats \\
\hline 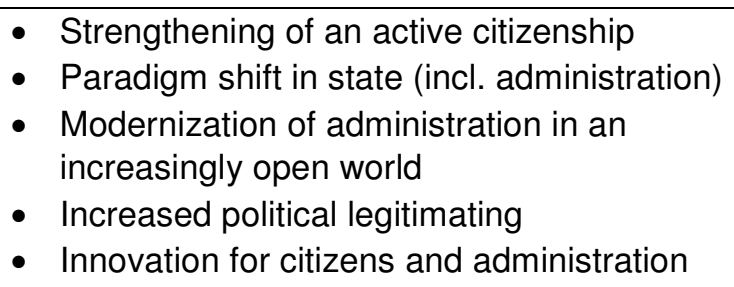 & $\begin{array}{ll}\text { - } & \text { Increased vulnerability to criticism } \\
\text { - } & \text { Missing Interpretive Predominance } \\
\text { - } & \text { Misinterpretation } \\
\text { - } & \text { Populist mobilization of masses } \\
\text { - } & \text { Attendance for a wide openness } \\
\text { - Ignorance of criticism and open platforms }\end{array}$ \\
\hline
\end{tabular}

Open Government Data can be compared to Open Private Data, which do not belong to the government or the administration, but which are data, owned by private persons, companies or non-profit organizations. Geiger describes the relation between Open Government Data and Open Private Data as followed:

"In contrast [to Open Government Data], Open Private Data is not enforcing the opening of government and administration as well as the excess of transparency, primary. The re-use and recovery of unmodified data can be possible but has not to. But open private data got also potential for boosting citizens participation. The increase of collaboration is limited because of the imperfect technical integration to the governmental system. So, a better governance in terms of collaboration by a better communication between citizens, politicians and administration is not possible. Open Innovation and increasing economic development can be realized partially but not in broad levels of the state. An advantage for efficiency and effectivity can be the autonomy of an organization. Otherwise, missing data standards, problems in data privacy and the lack of good prepared information, the quality of data and the continuity of the disposal of data were decisive problems of the usage of private data for governmental duties and responsibilities. Furthermore, the supply of private data creates a reactive attitude of the administration and not the intended proactive approach or the cultural change within administration and governance, which would be achieved by the supply of Open Government Data." (Geiger 2012) 


\section{Examples for Open Government Data}

There is a wide range of best-practices in the usage of Open Government Data. One can differ between (I) portals for the supply of the Open Government Data sets, (II) portals which provide not only the raw data sets of Open Government Data but also technical tools or developer kits for understanding and interpreting the provided Open Government Data. Additionally there are (III) existing portals, acting as showrooms for best practices, using Open Government Data. (IV), there are websites, offering programs or applications (apps) for smartphones, using the Open Government Data.

One of the first international examples for the provision of raw data sets within a portal is the portal in the United Kingdom, http://data.gov.uk. More than 8.500 data sets are offered in the Open Data Portal (29.11.2012).

In Germany, one of the first examples for an Open Data Portal is the portal of the state of BadenWürttemberg. At the moment, the portal is launched as "persistent beta" at http://opendata.servicebw.de. The portal is divided into three parts: (I) Data, (II) Applications and (III) Tools. In addition to Open Government Data, Data of Private Actors should be provided within this portal. A forecast for the usage of Open Government Data cannot be given at the moment. But supplementary to the known potentials, a main benefit of Open Government Data can be added in the matter of accountability. As a good example, the Open Data Portal Kenya should be mentioned. This three different Open Data Portals are showing, how different the subject of Open Data can be solved by different actors in different countries, depending on the aims of the providers and the culture of the users.

\section{Conclusion}

This article increases the awareness of Open Data and Open Government Data. By taking notice of these approaches, the benefits, advantages and opportunities, threats and weaknesses, the managers and employees can estimate the potential of free accessible government data. If managers, politicians and responsible persons see Open Government Data as one piece of a puzzle in the modernization process of public administration it must be classified, when and which data and applications should be first introduced, how and by whom in the implementation process. Variables could be an available time slot, the interests of economy and the existing engagement of associations, programmers and research institutions in the Open Government Data community. Synergistic effects can result from a reciprocal exchange and networking of the actors.

Viewed realistically, the understanding of using freely-accessible data will be identified step by step by administrations. Cooperation with the positions and being interested in opening their own data base will be preferred. To achieve the desired sustainability and achieve the goals, a mission statement-oriented strategy must be developed at an early stage. This statement contributes orientation and a framework for further steps for a fitting corporate strategy and an efficient implementation by the public authorities. It should contain guidelines for opening data sets and key performance indicators for the intended achievement of objectives. Simultaneously, traceable boundaries must be set for all actors for the definition of an acceptable and sustainable data opening process. Different user groups should be integrated to provide a large number of interests. These influences may be captured by the participation of communes, citizens, companies, associations and researchers in an open innovation process. Several decision criteria can prioritize the data sets in the publishing process: actuality of data, potential of annotation, improvement, transparency, economic potential and innovative capacity. Because of data privacy, publication of data must normally be evaluated. For an early understanding of risks and resistance, a prospective risk analysis is recommended, to estimate outcome and identify and reduce risks, conflicts or insecurities. Access to data sets in the internet is not the same thing as the locating and using of these data. But (re-)usage of the data can be boosted by well structured, machine-readable data catalogues including meta data, data portals and interfaces for an automatic data transfer. This automatic transfer is sense-making in context to dynamic provided data demands with fast- 
changing values or to proactive offers of public authorities. Especially, the target groups of Open Government Data, including citizens, companies, researchers and developers must be informed about news, innovations and solutions in freely-accessible public data by a responsible public press office. New publications formats, portals and competitions can extend the range and the reuse of data catalogues and opened datasets (von Lucke/Geiger, 2010). These approaches deliver the opening of stored data in a continuous dialogue. Administration should not only inform the public, but react acceptably by gathering and reviewing the demands and suggestions of users (Deloitte Research, 2010). Good input can create valuable stimulus for a more complex society in an open state. Each part of the society profits through the openness and transparency of public agencies by freely-accessible data, because they strengthen the belief in public action.

\section{References}

Berlin 2010: Land Berlin (2010). Online Voting zu Open Data. Auswertung der Online-Umfrage auf Berlin.de 2010, Senatsverwaltung für Wirtschaft, Technologie und Frauen, Berlin. Retrieved November 26, 2012, from http://www.berlin.de/projektzukunft/fileadmin/user upload/pdf/pr\%C3\%A4sentationen/auswertung Online Voting zu Open Data.pdf

Berners-Lee 2006: Berners-Lee, T. (2006). Linked Data - Design Issues, World Wide Web Consortium (W3C), London 2006. Retrieved November 26, 2012, from

http://www.w3.org/Designlssues/LinkedData.html

CCC 2010: Chaos Computer Club Deutschland (2010). Forderungen für ein lebenswertes Netz - 11 Thesen zur Deutschen Netzpolitik des Chaos Computer Clubs Deutschland, Berlin 2010. Retrieved November 26, 2012, from

http://www.ccc.de/de/updates/2010/forderungen-lebenswertes-netz

Corbett 2010: Corbett, P. (2010). How to run your own Apps for Democracy Innovation Contest, iStrategy Labs, Washington 2010. Retrieved November 26, 2012, from

http://www.appsfordemocracy.org/wp\%E2\%80\%90content/uploads/2010/01/create an apps for democracy.pdf

Davies 2010: Davies, T. (2010). Open data, democracy and public sector reform - A look at open government data use from data.gov.uk, Master theses at University of Oxford, Practical Participation, London 2010. Retrieved November 26, 2012, from

http://www.opendataimpacts.net/report/wp-content/uploads/2010/08/How-is-open-government-data-being-used-inpractice.pdf

Deloitte Research 2010: Macmillan, P. \& Eggers, W. D. \& Dovey, T. (2010). Unlocking government - How data transforms democracy, Deloitte Canada und Deloitte Research, Washington DC 2010.

Geiger 2012: Geiger, C. P. (2012). Linked Open Government Data, in: Anna Rozeva \& Roumiana Tsankova (Eds.): Management of Public and Business Administration Processes by Means of collaboration and Knowledge, Sofia 2012, S. 107-113.

Geiger/vonLucke 2011: Geiger, C. P. \& von Lucke, J. (2011). Open Government data, in: Parycek, Peter; Kripp, Manuel J. und Edelmann, Noella (Hrsg.): CeDEM11. Conference for E-Democracy and Open Government, Danube University Krems, Krems 2011, p. 183-194.

Gierow 2010: Gierow, H. J. (2010). Von der öffentlichen Verwaltung zur offenen Verwaltung, Opendata Network, Berlin 2010. Retrieved November 26, 2012, from

http://opendata-network.org/2010/06/von-der-offentlichen-verwaltung-zur-offenen-verwaltung

Granada-Strategy 2010: Ministerio de Industria, Turismo y Comercio (2010). Spanish Proposal for a Digital Europe: The Granada Strategy, Granada 2010. Retrieved November 26, 2012, from http://www.laquadrature.net/files/Granada Strategy-For a digital Europe.pdf

Gray 2009: Gray, J. \& Hatcher, J. \& Hogge, B. \& Parrish, S. \& Pollock, R. (2009). Unlocking the Potential of Aid Information, Version 0.2, Open Knowledge Foundation, London 2009. Retrieved November 26, 2012, from http://www.unlockingaid.info/wp-content/uploads/2010/02/UnlockingAidlnformation.pdf

Hansen/Neumann 2009: Hansen, H. R. \& Neumann, G. (2009). Wirtschaftsinformatik 1, Grundlagen und Anwendungen, Lucius \& Lucius Verlagsgesellschaft, Stuttgart 2009. 
IG Collaboratory 2010: Internet \& Gesellschaft Co:llaboratory (2010). Offene Staatskunst - Bessere Politik durch Open Government ?, Abschlussbericht, 1. Auflage, Berlin 2010. Retrieved November 26, 2012, from

http://dl.collaboratory.de/reports/Ini2 OffeneStaatskunst.pdf

Klessmann 2010: Klessmann, J. (2010). Open Data - Transparenz als Ressource für Ihre Kommunen und Bürger, Opendata Network e.V. und Government 2.0 Netzwerk Deutschland e.V., Berlin 2010.

von Lucke/Geiger 2010: von Lucke, J. \& Geiger, C. (2010). Open Government Data - Frei verfügbare Daten des öffentlichen Sektors, Gutachten für die Deutsche Telekom AG zur T-City Friedrichshafen, Version vom 03.12.2010, Deutsche Telekom Institute for Connected Cities, Zeppelin University, Friedrichshafen 2010. Retrieved November 26, 2012, from

http://www.zeppelin-university.de/deutsch/lehrstuehle/ticc/TICC-101203-OpenGovernmentData-V1.pdf.

von Lucke 2011: von Lucke, J. (2012). Open Government Collaboration. Offene Formen der Zusammenarbeit beim Regieren und Verwalten. Gutachten für die Deutsche Telekom AG zur T-City Friedrichshafen, Version vom 25.10.2012, Deutsche Telekom Institute for Connected Cities, Zeppelin Universität, Friedrichshafen 2012. Retrieved November 26, 2012, from http://www.zu.de/deutsch/lehrstuehle/ticc/JvL-121025-OpenGovernmentCollaborationV1.pdf

von Lucke 2011: von Lucke, J. (2011). Innovationsschub durch Open Data, Datenportale und Umsetzungswettbewerbe, in: Schauer, Reinbert; Thom, Norbert und Hilgers, Dennis (Hrsg.): Innovative Verwaltungen - Innovationsmanagement als Instrument von Verwaltungsreformen, Johannes Keppler Universität Linz, Linz 2011, in printing.

Lundy 2010: Lundy, K. (2010). Gov 2.0 building a strong foundation for open democracy, CeBIT 2010, Hannover 2010.

MICUS 2003: Fornefeld, M. \& Oefinger, P. \& Rausch, U. (2003). Der Markt für Geoinformationen: Potenziale für Beschäftigung, Innovation und Wertschöpfung, MICUS Management Consulting GmbH, Düsseldorf 2003.

North 1998: North, K. (1998). Wissensorientierte Unternehmensführung - Wertschöpfung durch Wissen, Gabler Verlag, Wiesbaden 1998.

OKF 2006: Open Knowledge Foundation (2006). Open Knowledge Definition (OKD), Open Knowledge Foundation, London 2006. Retrieved November 26, 2012, from

http://www.opendefinition.org/okd

Open Data Working Group 2007: Open Data Working Group (2007). Open Government Data Principles, Open Data Working Group, Sebastopol 2007. Retrieved November 26, 2012, from http://www.opengovdata.org/home/8principles

Opendata Network 2010: Opendata Network e.V. (2010). 10 Prinzipien offener Regierungsinformationen, Opendata Network e.V., Berlin 2010. Retrieved November 26, 2012, from http://wiki.opendata-network.org/Ten Principles for Opening Up Government Information

Reinermann 1986: Reinermann, H. (1986). Beitrag des Seminars „Informationssysteme für den Bürger und für die Verwaltungsführung" zur International Design Competition for an Advanced Information City: Campus City Kawasaki, Speyerer Arbeitshefte, Band 75, Hochschule für Verwaltungswissenschaft Speyer, Speyer 1986.

Schieferdecker 2010: Schieferdecker, I. (2010). Öffentliche Daten des Landes Berlin, XInnovations Konferenz, Fraunhofer Institut FOKUS, Berlin 2010.

Sunlight Foundation 2010: Sunlight Foundation (2010). Ten Principles for Opening Up Government Information, Sunlight Foundation, Washington DC 2010. Retrieved November 26, 2012, from http://sunlightfoundation.com/policy/documents/ten-open-data-principles/

Tauberer 2009: Tauberer, J. (2009). An Information Goldmine, Open To All, in: E-Government Bulletin vom 04. September 2009, Headstar Publications, London 2009.

Torkington 2010: Torkington, N. (2010). Rethinking Open Data, O’Reilly Radar, Sebastopol 2010. Retrieved November 26, 2012, from http://radar.oreilly.com/2010/02/rethinking-open-data.html

\section{About the Authors}

Christian P. Geiger, M.A.

Works as research assistant at the Deutsche Telekom Institute for Connected Cities (TICC) at the Zeppelin University Friedrichshafen. After receiving his Bachelor of Arts in Political and Administrative Science from the University of Constance, he finished his Master of Arts in Public Management and Governance at the Zeppelin University Friedrichshafen. Geiger focuses on City Wikis, Smart Cities and Public Sector Modernization. 
Prof. Dr. Jörn von Lucke

Is university professor at the chair for Administrative and Business Informatics at the Deutsche Telekom Institute for Connected Cities (TICC) at Zeppelin University Friedrichshafen. As director of the institute, he is engaged in various projects concerning information and communication technologies in the T-City Friedrichshafen. In 2007, Jörn von Lucke has made his postdoctoral thesis about 'High Performance Portals for Public Administrations' at the German University of Administrative Sciences Speyer. In 1999 he received his doctor's degree from the German University of Administrative Sciences Speyer for "Increased Efficiency and Cost Savings through Internet Technologies for Retirement Insurance Agencies." In 1996, von Lucke received his Diploma in Business Informatics from the University of Mannheim. 